\title{
O município de Cajueiro da Praia (PI), Brasil: características naturais e a conservação de um patrimônio socioambiental
}

\author{
The city of Cajueiro da Praia (PI), Brazil: natural features and the \\ conservation of a social and environmental heritage
}

André da Silva Dutra ${ }^{1}$

andredutrinha3@ifma.edu.br

\author{
Raquel Maria Fontes do Amaral Pereira ${ }^{2}$ \\ raquelfontespereira@gmail.com
}

\section{Resumo}

O trabalho descreve as características naturais do litoral piauiense, especialmente do município de Cajueiro da Praia, objetivando promover uma reflexão sobre a conservação deste ambiente como patrimônio socioambiental. Desta forma, realizou-se uma pesquisa bibliográfica com enfoque qualitativo, caracterizando geograficamente a região e identificando os segmentos de atividade turística que incentivam a conservação das características naturais locais através da conscientização ambiental. No decorrer do estudo, foi possível verificar que o ecoturismo é a principal atratividade turística das praias cajueirenses, embora ainda sejam necessárias campanhas de sensibilização e conscientização ambientais mais eficazes por parte do poder público do estado do Piaú e da Prefeitura Municipal de Cajueiro da Praia, que promovam, de fato, o turismo na região de maneira sustentável, de modo a contar com a participação efetiva das comunidades locais em todas as etapas deste processo. Também é necessário criar Unidades de Conservação para garantir efetivamente a preservação das características naturais do município de Cajueiro da Praia como um patrimônio socioambiental.

Palavras-chave: Cajueiro da Praia; Características naturais; Patrimônio socioambiental.

\begin{abstract}
This paper describes the natural features of the Piauí coast, especially the city of Cajueiro da Praia, seeking to promote a reflection on the conservation of this place as a social and environmental heritage. Thus, a bibliographical research with a qualitative approach was done in order to characterize geographically the region and identify the touristic segments that encourage the conservation of local natural features through environmental awareness. During the work, we found that Ecotourism is the main touristic activity of cajueirenses beaches. But more environmental awareness campaigns are necessary from the government of the Piauí state and the city of Cajueiro da Praia in order to promote, in fact, the tourism in the region in a sustainable manner and with an effective participation of local communities in all stages of this process. It is also necessary to create protected areas to ensure the preservation of the natural characteristics of Cajueiro da Praia as an environmental heritage.
\end{abstract}

Keywords: Cajueiro da Praia; Natural features; Social and environmental heritage.

1 Aluno do Programa de Mestrado em Turismo e Hotelaria da Universidade do Vale do Itajaí. Especialista em Educação Física Escolar. Professor de Educação Física do Instituto Federal do Maranhão.

2 Professora do Programa de Mestrando em Turismo e Hotelaria da Universidade do Vale do Itajaí. Doutora em Geografia pela niversidade de São Paulo. Professora do Programa de Pós-Graduação em Geografia da Universidade Federal de Santa Catarina. Bolsista de produtividade em pesquisa - nível 2 do Conselho Nacional de Desenvolvimento Científico e Tecnológico (CNPq). 


\section{Introdução}

Com apenas $66 \mathrm{~km}$ de extensão, o litoral piauiense é extremamente importante para a biodiversidade marinha por abrigar diversas espécies ameaçadas de extinção como o peixe-boi marinho em seu habitat natural no municipio de Cajueiro da Praia e as tartarugas de couro e de pente, cuja reprodução era registrada apenas no litoral do Espírito Santo, pode ser registrada também nas praias piauienses da Pedra do Sal e de Barra Grande.

De acordo com a Organização para a Educação, Ciência e Cultura das Nações Unidas (Unesco, 1972), o Património Natural designa algo com características físicas, biológicas e geológicas extraordinárias; habitats de espécies animais ou vegetais em risco; e áreas de grande valor do ponto de vista científico e estético, ou do ponto de vista da conservação. Já o Patrimônio Cultural de uma nação, de uma região ou de uma comunidade é composto de todas as expressões materiais e espirituais que lhe constituem, incluindo o meio ambiente natural (Declaração de Caracas,1992).

Para Delphim (2004), a preservação do patrimônio natural propicia excelente exercício de integração entre os elementos físicos e biológicos da natureza, os sistemas que estabelecem entre si e com as ações humanas, fornecendo chaves para a proteção sinérgica de sítios e formações naturais significativas, em conjunto e harmonia com as comunidades de plantas, animais e seres humanos, sobretudo com a cultura de cada grupo em relação à natureza, pois é nela que se encontra toda a fonte material e imaterial da produção cultural.

De certa forma, estes conceitos não podem existir isoladamente; pelo contrário, devem se complementar através da conservação dos sítios culturais para proteger as áreas naturais e paisagísticas no mundo, como um legado para o presente e para o futuro da humanidade, pois a inter-relação entre o homem, os seus semelhantes e tudo que os envolvem, como o meio ambiente, a fauna, a flora, o ar, os minerais, os rios, os oceanos, os manguezais, assim como tudo aquilo que eles contêm, acaba interagindo e até mesmo interferindo no cotidiano de diferentes grupos sociais.

Este artigo, portanto, procura destacar as características naturais do município de Cajueiro da Praia, localizado no litoral piauiense, identificando quais segmentos da atividade turística incentivam a conservação destas características através da conscientização ambiental, objetivando promover uma reflexão sobre a importância da preservação deste ambiente como patrimônio socioambiental.

\section{O litoral Piauiense: breve caracterização}

O litoral do estado do Piauí está localizado entre os litorais do Ceará e do Maranhão. É constituído por quatro municípios: Parnaíba, Ilha Grande, Luis Correia e Cajueiro da Praia, sendo considerado o menor litoral em extensão dentre os estados costeiros brasileiros, conforme demonstrado na Figura 1, ao lado.

Situado na Área de Proteção Ambiental (APA)

Figura 1 - Localização geográfica do litoral piauiense: praias de Cajueiro da Praia (PI).

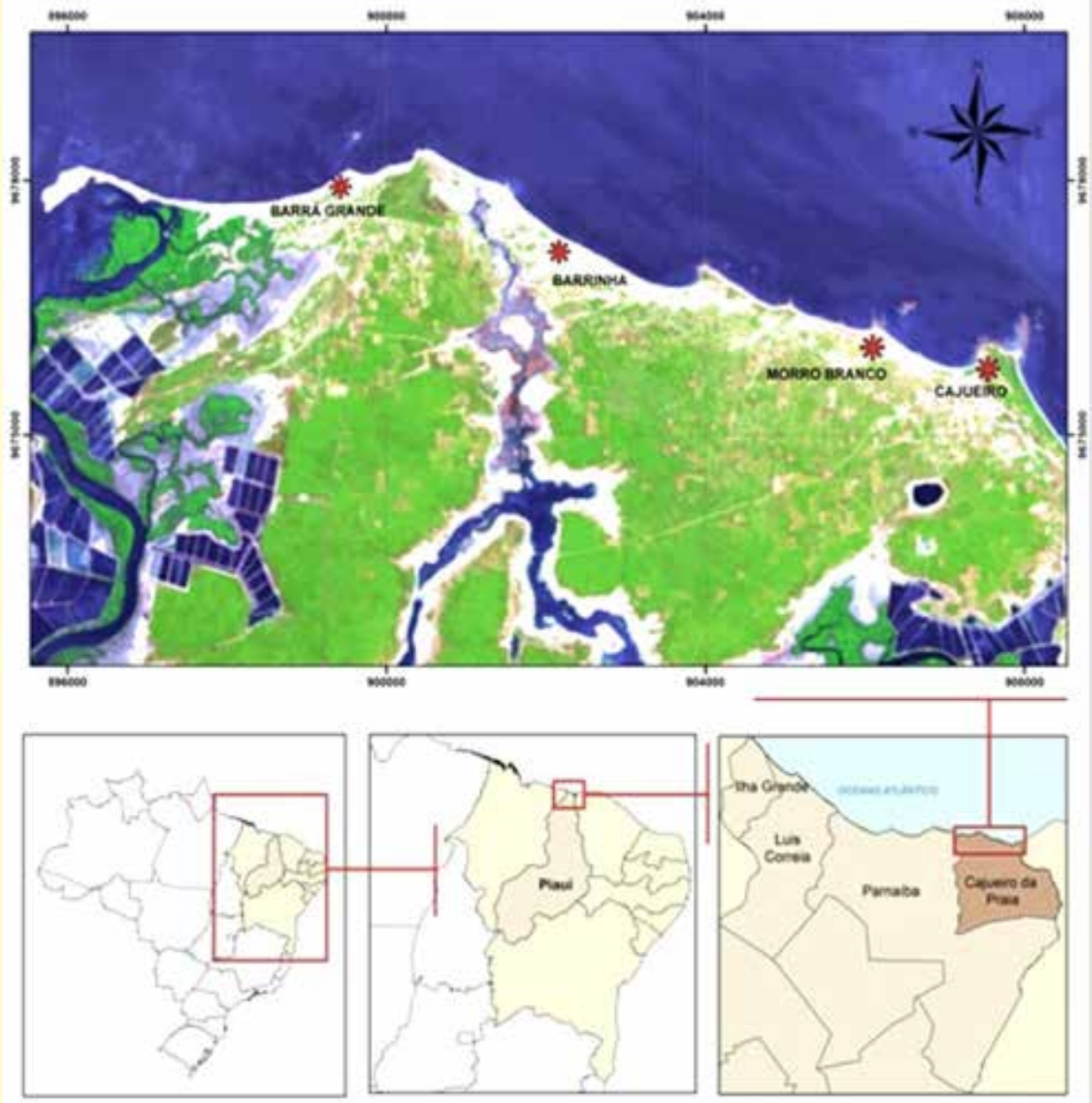

Fonte: Elaborado pelos autores. 
Polo Costa do Delta, por muito tempo foi considerado apenas uma passagem entre Jericoacoara e os Lençóis Maranhenses, a famosa Rota das Emoções ${ }^{3}$. A parada muitas vezes era feita somente para conhecer o deslumbrante Delta do Parnaíba. Só agora o pequeno litoral do estado vem sendo considerado um ponto de parada quase obrigatório na viagem, por conta de sua situação privilegiada, conforme destacam Cavalcanti (2000), Costa (2008) e Carvalho (2010).

A capital do estado do Piauí é a cidade de Teresina, situada a $350 \mathrm{~km}$ do litoral. Teresina representa o portão de entrada para que os turistas conheçam os principais produtos turísticos do estado, por se encontrar num importante entroncamento rodoviário, que interliga os estados do Nordeste à região Norte e facilita a comunicação com os principais centros urbanos das regiões Centro-Oeste e Sudeste.

Além do transporte rodoviário, Teresina possui um aeroporto local onde atuam as principais companhias aéreas do Brasil (Gol, Tam e Azul), que transportam pessoas diariamente para as diferentes regiões do país, inclusive para Parnaíba, cidade localizada no litoral piauiense, apesar de seu aeroporto não atender aos padrões internacionais. Cajueiro da Praia fica a $55 \mathrm{~km}$ de Parnaíba e o acesso a se dá por Parnaíba, através de uma estrada densa ou por Luis Correia, por meio de uma estrada que percorre o litoral piauiense.

Para Baptista (1981), a zona costeira piauiense começa na Barra das Canárias, seguindo pela Ilha de Santa Isabel, que apresenta formas litorâneas retificadas sucessivas, entre a Barra do Igarassu e as Canárias. O litoral piauiense, de acordo com Baptista (2012), possui uma diversidade de feições distribuída por seus $66 \mathrm{~km}$ de extensão, cujas características estão associadas ao seu embasamento geológico, principalmente à ocorrência de recifes de arenito.

De acordo com a classificação de Köppen, o clima litorâneo piauiense é do tipo tropical, quente e úmido (Aw'), com alto índice de pluviosidade em decorrência da influência da massa Equatorial Atlântica, entre os meses de janeiro e junho. Geologicamente, a região encontra-se sobre duas formações: depósitos de areias quartzosas do Quaternário, situados mais a oeste e chegando até os limites com o Maranhão; e formação de barreiras de idade Terciária, situadas mais a leste, até os limites com o Ceará (JACOMINE et al, 1986; SOUSA \& RODRIGUES NETA, 2006).

Para Castro (2007), o litoral piauiense apresenta extensas planícies flúvio-marinhas, que cortadas por uma rede de canais, formam as ilhas do Delta. Como resultado dos processos de acumulação flúvio marinha e da influência das características destes ambientes, desenvolvem-se as áreas de mangues, as dunas e as áreas de tensão ecológica, constituídas por caatinga a leste, por cerrado a sudoeste e por sistemas marinhos ao norte.

Segundo o Centro de Pesquisas Econômicas e Sociais do Piauí (Cepro, 1996), a classificação das principais formações vegetais do litoral piauiense é caracterizada como: vegetação pioneira psamófila (de terrenos arenosos), vegetação subperenifólia de dunas, vegetação perenifólia de mangue, vegetação de várzea, vegetação do delta dos rios Parnaíba e Longá, vegetação dos tabuleiros e vegetação estacional secundária do cerradão.

De acordo com o Plano de Desenvolvimento Integrado do Turismo Sustentável (PDITS) - Polo Costa do Delta (2009), o Delta do Parnaíba, localizado entre os estados do Piauí e Maranhão, especificadamente nos municípios de Parnaíba, Ilha Grande e Luis Correia (PI), Araiozes e Tutóia (MA), possui mais de setenta ilhas fluviais em cinco braços do rio Parnaíba, que abrigam diversas espécies de animais, conforme demonstrado na Figura 2.

3 A Rota das Emoções corresponde a um roteiro que liga três estados do Nordeste brasileiro: Ceará (Parque Nacional de Jericoacara), Piauí (Área de Proteção Ambiental Polo Costa do Delta) e Maranhão (Parque Nacional do Lençóis Maranhenses). Possui um ecossistema variado e apresenta mares de ondas perfeitas, próprias para a prática do surf, windsurf, kitesurf, entre outros esportes náuticos. Toda a Rota das Emoções é envolta em muita aventura e a região, por manter suas características naturais bastante preservadas, virou roteiro obrigatório para os amantes do ecoturismo, do turismo de aventura e dos esportes ao ar livre. 


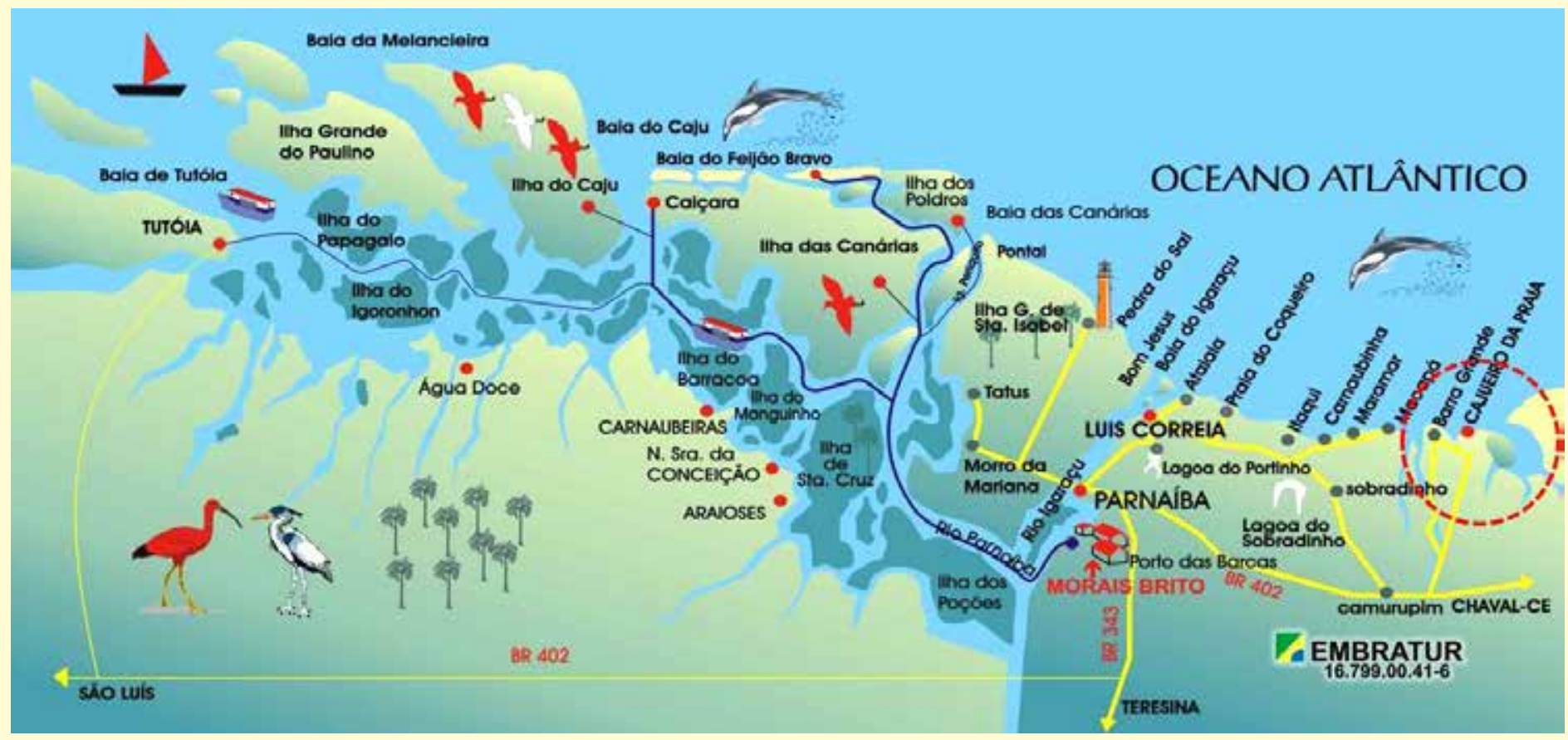

Fonte: Embratur (2015).

De acordo com Guzzi (2012), ocorrem no litoral piauiense as cinco espécies brasileiras de tartaruga marinha: Caretta caretta ou tartaruga cabeçuda; Chelonia mydas ou tartaruga verde; Eretmochelys imbricata ou tartaruga de pente; Lepidochelys olivacea ou tartaruga oliva; e Dermochelys coriacea ou tartaruga de couro.

Outra espécie ameaçada de extinção encontrada no litoral piauiense é o mamífero aquático peixe-boi marinho (Trichechus manatus), que pode ser observado em seu habitat natural no município de Cajueiro da Praia, onde há uma base do Projeto Peixe-Boi Marinho ${ }^{4}$, de responsabilidade do Centro de Mamíferos Aquáticos (CMA) e do Instituto Chico Mendes de Conservação da Biodiversidade (ICMBio).

Assim, o valor turístico do Polo Costa do Delta é reforçado pela predominância destes espaços naturais e, em especial, costeiros, cujas singularidades chamam a atenção para a destinação turística, especialmente em razão de sua natureza, praticamente intocada e inexplorada pela ação humana.

Apesar de o litoral piauiense apresentar características singulares que representam potencialidades para o desenvolvimento do turismo e que o diferenciam do litoral dos demais estados nordestinos, essa atividade ocorre, em toda a extensão litorânea do estado, de forma desorganizada e somente nos períodos considerados de alta estação que correspondem às férias escolares.

\section{O Município de Cajueiro da Praia (PI), Brasil: belezas naturais e importância da conservação de um patrimônio socioambiental}

Cajueiro da Praia é um dos municípios beneficiados pelo Programa de Regionalização do Turismo, do Ministério do Turismo (MTur), e faz parte da região turística Polo Costa do Delta, juntamente com as cidades de Luís Correia, Parnaíba e Ilha Grande, que compõem o roteiro do Piauí Surpreendente, um dos 87 roteiros turísticos divulgados pelo Ministério (SETUR, 2010).

4 O Projeto Peixe-Boi Marinho é o único no planeta em que é executado o monitoramento das espécies em mar aberto. É realizado pelo Instituto Brasileiro de Meio Ambiente e Recursos Naturais Renováveis (Ibama), em cogestão com a Fundação Mamíferos Aquáticos e com patrocínio oficial da Petrobrás, além de parceria com a prefeitura e apoio das comunidades locais de 06 unidades estrategicamente instaladas no litoral nordestino: Alagoas, Paraíba, Pernambuco, Ceará, Maranhão e Piauí. Cajueiro da Praia foi o primeiro município brasileiro a conceder o título de patrimônio natural ao peixe-boi marinho, quando registrou, em 2005, o nascimento de um filhote da espécie. Ao todo, nasceram no local quatro filhotes. Colaboradores do projeto e pescadores da região informaram aos técnicos e veterinários do Ibama a ocorrência de um parto registrado naturalmente, sem interferência humana, de fêmea nativa, a uma distância de cinco metros da linha de praia. O filhote nasceu com aproximadamente 1,30 m e a mãe é uma fêmea juvenil. O mamífero é o símbolo do lugar e foi adotado como Patrimônio Natural do município. 
O município possui uma faixa litorânea de 13 quilômetros e, apesar de possuir 20 povoados, esse trabalho aborda apenas os povoados de sua orla marítima, onde a atividade turística se consolidou (Barrinha, Morro Branco, Cajueiro e Barra Grande), conforme demonstrado na Imagem 3, especialmente na praia de Barra Grande, a mais extensa delas, que se destaca das demais pelo expressivo crescimento do turismo nas últimas décadas.

A praia de Barrinha é uma praia tranquila e considerada um refúgio por não dispor de estrutura física adequada para acolher os turistas. $\mathrm{O}$ turismo de esportes, porém, começa a ser explorado na região com a prática do kitesurf e a realização de eventos esportivos da modalidade. A praia é habitada, em sua maioria, por nativos ou pessoas que venderam seus terrenos em Barra Grande. A pequena vila de casinhas coloridas e muros floridos, obra de uma artesã local, é um local perfeito para ser explorado através de caminhada ou pedaladas.

A praia de Morro Branco é ocupada por uma pequena colônia de pescadores e, assim como a praia de Barrinha, também não é regularmente frequentada por turistas por não dispor de uma estrutura que promova o turismo na região. $\mathrm{Na}$ beira da praia existem algumas casas de veraneio utilizadas pelos proprietários no período de suas férias.

A praia de Cajueiro possui este nome em homenagem a um grande pé da fruta que existe no local. Apesar de ainda ser pouco frequentada por turistas, dispõe de elementos naturais que favorecem a prática de esportes náuticos como o kitesurf, a caminhada e o SUP5.

A praia de Barra Grande recebe o maior fluxo de turistas dentre as praias que compõem o município de Cajueiro da Praia devido ao fato de ser um paraíso ainda não descoberto pelo turismo de massa. A praia também é alvo de visitas dos adeptos dos esportes de aventura, devido ao seu enorme potencial ecoturístico e do turismo de esportes.

De acordo com Macedo (2012), a visitação à praia de Barra Grande remonta ao início da década de 70 do século XX, quando veranistas oriundos de algumas cidades dos estados do Piauí e do Ceará, ali chegavam para passar suas férias. A partir das décadas de 1980 e 1990, estes turistas passam a visitar a praia para fins de veraneio, em sua grande maioria, através de excursões organizadas por grupos de amigos em ônibus alugados, sem haver a interferência de agências de viagens vendendo pacotes turísticos para Barra Grande.

Ainda segundo Macedo (2011), um novo destino turístico passa a se configurar, a partir de 2000, na

Imagem 3 - Imagem aérea da Praia de Barra Grande.

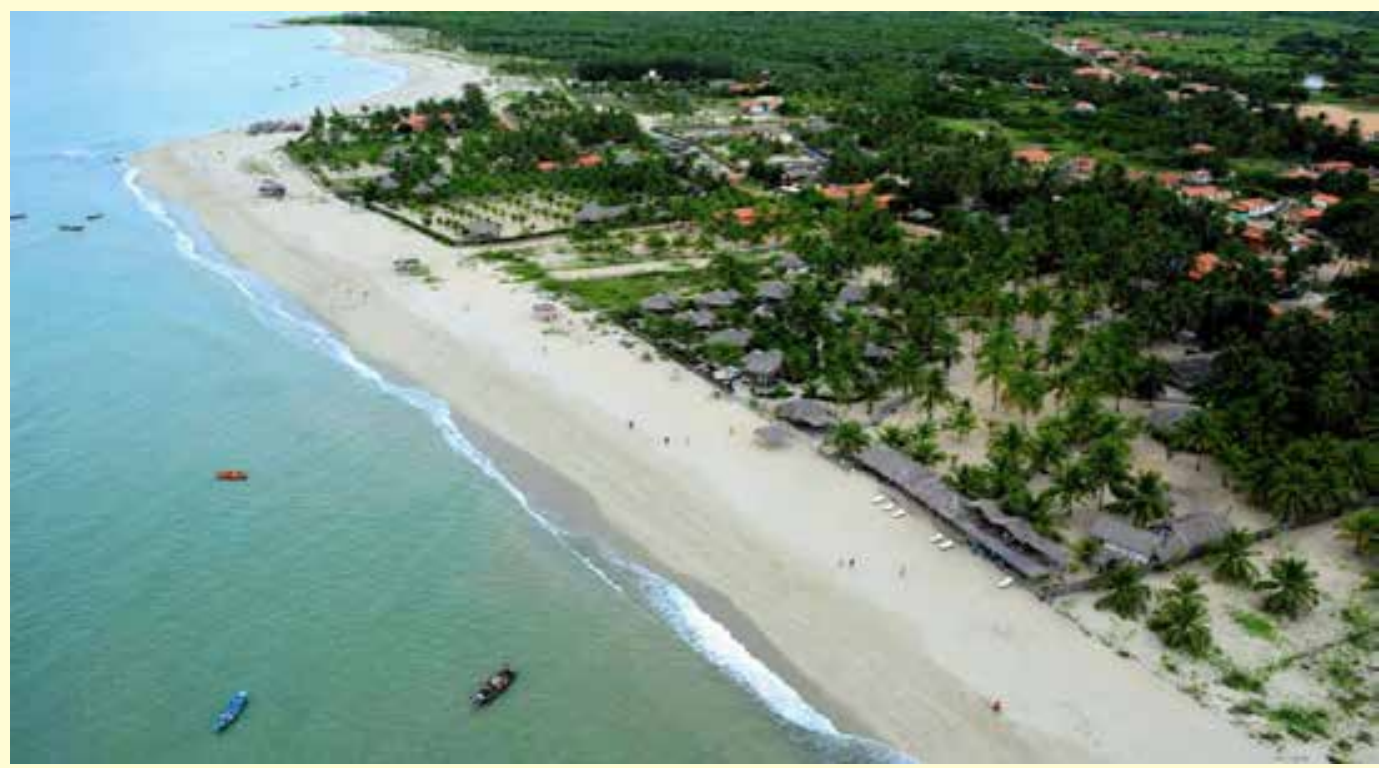

Fonte: Jornal da Parnaíba (2015). praia de Barra Grande, com a introdução da prática do kitesurf pelo empresário e médico teresinense Ariosto Ibiapina, no ano de 2005, o qual, reconhecendo o crescimento desta prática esportiva no município de Jericoacara (CE), foi motivado a abrir a pousada Barra Grande Kite Camp (BGK), oferecendo suporte para os praticantes e simpatizantes do kitesurf em Barra Grande.

Desta forma, com a

5 Stand Up Paddle Boarding, ou SUP, é um desporto aquático, uma variante do surf, no qual o praticante fica em pé numa prancha, e usa um remo para se mover através da água. O Stand Up Paddle Boarding, com raízes Polinésias, significa em havaiano Ku (de pé) Hoe (remar) He'e (surfar) Nalu (onda). 
exploração e consequente difusão do kitesurf na praia de Barra Grande, facilitada principalmente pelo aproveitamento dos ventos alísios ${ }^{6}$, o trade turístico local começa a se organizar para movimentar recursos e atrair investidores que ali se fixam construindo moradias ou abrindo estabelecimentos comerciais, principalmente pousadas para acolher os turistas.

A partir deste investimento local, um novo tipo de turista, com maior poder aquisitivo e situado na faixa etária dos 17 aos 30 anos de idade, passa a frequentar a praia. Assim, com o aumento do fluxo, o Governo do Estado e o Serviço de Apoio às Micro e Pequenas empresas do Piaú (Sebrae/PI) começaram a promover o envolvimento da população local no turismo.

O destaque de Barra Grande pelo segmento do turismo de esportes é hoje respaldado pelo Ministério do Turismo e pelo Instituto Brasileiro de Turismo (Embratur), através da prática do kitesurf. Esse potencial do esporte como atrativo e produto turístico movimenta recursos e atrai investidores que, aos poucos, vêm adquirindo terras para fixação de moradia, comprando e abrindo estabelecimentos comerciais.

Lopes (2012) destaca que, quanto à organização espacial, o surgimento de novos empreendimentos em Barra Grande acabou gerando muitos atritos e uma disputa pelo território que levou à exclusão e marginalização da comunidade local, pouco beneficiada pelos aspectos positivos que o turismo pode oferecer.

Por outro lado, começam a ocorrer pequenas transformações nas concepções de alguns moradores de Cajueiro da Praia com relação às responsabilidades sociais, principalmente por parte dos pescadores locais da Praia de Barra Grande, que passaram a criar associações e a atender aos turistas de maneira mais sustentável e profissional. É o caso da Associação dos Condutores de Barra Grande (Barratur) e da Nativos - Arte e Turismo, que oferecem roteiros em que os visitantes percorrem uma trilha entre os mangues e outras vegetações típicas do local, com duração média de três horas eduas paradas: uma para a observação de um cultivo de ostras, com

Imagem 4 - Trilha ecológica Camboa dos Cavalos Marinhos.

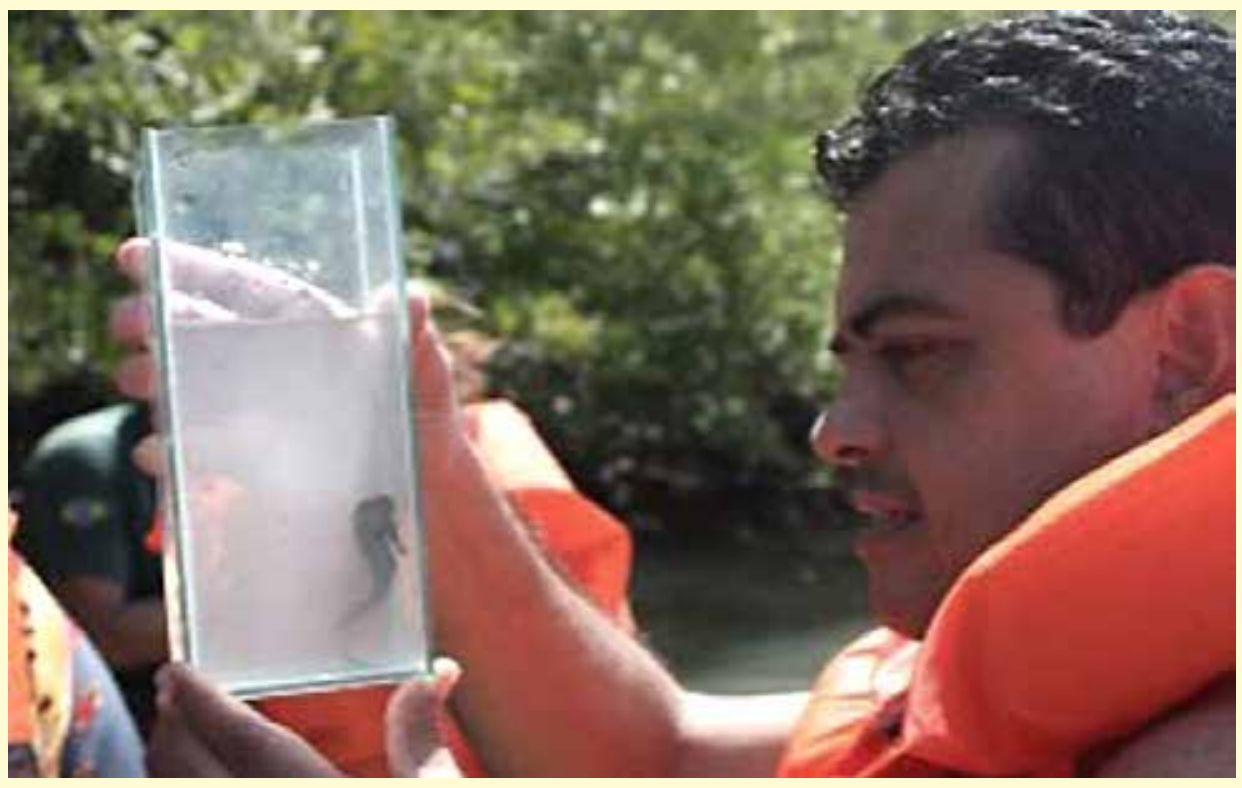

Fonte: Setur/PI (2015) degustação do marisco, e outra na Camboa dos Cavalos Marinhos, para observar os cavalos marinhos da espécie Hippocampus reidi, conforme demonstrado na Imagem 4.

De acordo com Barbosa e Perinotto (2010, p. 7), além do cavalo marinho, a trilha oferece contato direto com a fauna e flora existentes. Segundo alguns turistas, não seria apenas o cavalo marinho que os deixa fascinados, mas o conjunto de todo o cenário observado durante o trajeto como: crustáceos, diversas aves, mariscos, peixes e vegetação nativa, especialmente o mangue vermelho (Rhizophora mangle) que, unidos, incrementam o passeio. Tais atividades estão em consonância com o que salientam Virgino e Fernandes (2011), ao destacarem que a responsabilidade socioambiental é um fator capaz de agregar valor à cadeia do turismo, através de um trabalho conjunto de entidades ligadas ao governo, à iniciativa privada e à sociedade civil organizada, visando estabelecer ações que promovam a cidadania.

Nesse sentido, segundo Kotler (1996), as responsabilidades sociais são atribuições que a sociedade

6 Os alísios são ventos regulares que sopram constantemente, em superfície, das regiões de altas pressões atmosféricas subtropicais, situadas em ambos os hemisférios nas latitudes de aproximadamente $30^{\circ}$, para as de baixas pressões próximas à Linha do Equador. Por serem bastante intensos em toda a costa litorânea piauiense durante todo o ano (principalmente entre os meses de agosto, setembro e outubro, chegando a velocidades superiores a $7 \mathrm{~m} / \mathrm{s}$ ), favorecem a prática de esportes náuticos na região como o surf, o kitesurf e o windsurf. 
estipula para as instituições, tendo por objetivos definir algumas obrigações relacionadas à preservação do meio ambiente, dos direitos das minorias e das populações estabelecidas no local (nativas ou não). No entanto, muitos empresários do setor turístico, infelizmente, ainda entendem que sua responsabilidade social está relacionada exclusivamente ao turista e se restringem apenas ao cumprimento da obrigação legal de oferecer-lhe o que é prometido nas divulgações para venda de pacotes e ofertas turísticas. Essa, evidentemente, é uma visão muito estreita da questão.

De acordo com Beni (2001), no cenário nacional surgiu recentemente um avanço no sistema de parceria em virtude da falência do Estado na solução dos problemas sociais com responsabilidade e justiça. O próprio governo federal vem conferindo ênfase à formação de organizações sociais. As responsabilidades sociais no turismo podem, assim, amenizar os impactos negativos através de ações que interfiram nas atividades desenvolvidas pelo trade turístico, minimizando possíveis danos ao meio ambiente e, mais especificamente, à sociedade de Cajueiro da Praia.

Na praia de Barra Grande, já se percebe uma série de impactos negativos provocados pela presença dos turistas, bem como pela construção de empreendimentos do setor. Infelizmente, no estado do Piauí o turismo só há poucos anos foi reconhecido e encarado como política pública de interesse estadual. A Secretaria Estadual do Turismo foi criada apenas em 2007, o que aponta uma nova fase para a atividade turística, especialmente na região litorânea do estado (MACEDO, 2010).

No entanto, essa nova fase deve requerer que o trade local de Cajueiro da Praia se articule, planeje e aja de forma proativa no tocante à preservação dos seus recursos naturais e culturais, sem esperar por iniciativas do governo e impedindo que os empresários que representam o turismo da região se comportem de forma descompromissada frente ao desenvolvimento deste destino.

A Praia de Barra Grande foi contemplada com um planejamento exclusivo para o setor turístico, através de uma parceria entre o Sebrae/PI e a Secretaria Municipal de Turismo e Meio Ambiente, que resultou no Plano do Turismo de Barra Grande (2007, p. 5), para o período de 2008 à 2013. O plano estabeleceu como visão de futuro "ser modelo de turismo sustentável no Estado do Piauŕ", com a missão de "levar os turistas a conhecerem os recursos naturais e culturais de Barra Grande resultando em um maior desenvolvimento local". Foram traçados como principais objetivos: diminuir a sazonalidade, melhorando os impactos positivos do turismo para a economia local; aumentar a satisfação do turista que vem à Barra Grande, objetivando assim o seu retorno; e gerar mais renda e mais emprego para a população local.

Nesse sentido, diante da necessidade de adoção de planejamentos turísticos consistentes, Anjos (2004) propõe um modelo de planejamento e gestão do território turístico que busca criar processos integrados e com dinâmicas próprias, cujo foco principal de atuação deve ser a articulação de planos estratégicos que desencadeiem ações que envolvam questões sociais, econômicas, naturais, democráticas e sustentáveis do território turístico.

O Plano Estratégico de Barra Grande, entretanto, está longe de atender às necessidades básicas de um planejamento sistêmico nos requisitos da visão processual, integração entre as partes envolvidas e comprometimento na validação do plano proposto.

Segundo Carvalho (2010), a Praia de Barra Grande apresenta dois mundos diferentes, que apesar de próximos territorialmente, se encontram distantes cultural e estruturalmente. O elemento que separa esses dois mundos é a distância social, cultural e econômica resultante de políticas públicas que priorizam o lado mais forte da relação: os empresários em detrimento das pessoas da comunidade local.

Deste modo, constata-se que o turismo em Barra Grande do Piauí pode ser um fator indutor para o desenvolvimento sustentável da região e, se bem estruturado (com base em instrumentos consistentes de planejamento e gestão do território, que contem com a participação do governo, da comunidade local e dos empreendedores), poderá atrair mais turistas, gerando renda e melhoria da condição de vida da população.

Macedo (2012) afirma que o aspecto comercial do turismo é de pouco interesse por parte do poder público, que não promove uma maior divulgação do local. A Secretaria Estadual de Turismo (Setur) divulga o município, especialmente a Praia de Barra Grande, através de matérias promocionais turísticas do Piauí e da participação em eventos turísticos, como por exemplo o Brasil National Tourism Market (BNTM), da Bolsa Nacional de Turismo do Mercosul (Santa Catarina), a Feira Broztoa (São Paulo), o Salão do Turismo (São Paulo), o Festival De’lla Creativitá (Itália) e a Feira das Américas (ABAV). 
As agências de turismo do Piauí despertaram recentemente para a realização de pacotes turisticos para o município, mas boa parte do turismo local ainda ocorre por conta própria dos turistas, o que diante da precária estrutura da região, ainda é visto como um aspecto positivo, levando-se em conta os prejuízos socioambientais que o turismo em massa poderia ocasionar.

Além do aspecto promocional, a gestão municipal deve direcionar suas ações à causa do turismo com mais empenho. O plano de Fortalecimento da Gestão Municipal do Município de Cajueiro da Praia, de 2009, demonstra que o município não exerce de forma satisfatória o planejamento, a gestão e o monitoramento da atividade turística, em especial para Barra Grande.

Nesse sentido, a principal característica de um patrimônio é que a sua conservação seja de interesse público, quer por sua vinculação a fatos memoráveis da história do lugar e de seu povo, quer por seu excepcional valor arqueológico, etnográfico, bibliográfico ou artístico.

Segundo Neto (2006), Cajueiro da Praia foi o primeiro município brasileiro a receber o título de Patrimônio Natural do Peixe-Boi Marinho. A Lei Municipal no 51, de 12 de março de 2003, torna a prefeitura local responsável em proteger o peixe-boi marinho em seu habitat natural (estuários, rios e mar), além de poder explorar este título para incrementar a atividade turística e articular parcerias com entidades para preservar a espécie.

De acordo com Macedo (2012), desde 1994 os trabalhos do Projeto Peixe-Boi Marinho são realizados no município de Cajueiro da Praia e, com a criação de uma unidade deste projeto em parceria com a Fundação Mamíferos Aquáticos e patrocínio oficial da Petrobrás, especialistas e moradores locais uniram esforços por meio de ações ambientais em escolas e comunidades da região.

Segundo Carvalho e Araújo (2009), em 12 de setembro de 2008 foi inaugurada a nova base piauiense deste Projeto Peixe-Boi Marinho, contando com um Centro de Convivência, onde são expostos filmes educativos; um Museu, com acervo sobre a biodiversidade marinha, fauna e flora da região; uma Eco-oficina, onde são confeccionados produtos com a imagem do peixe-boi; uma loja de artesanato e uma Ecoloja; um alojamento para pesquisadores; uma lanchonete; uma sala de pesquisa e um tanque para reabilitação de animais.

Em Cajueiro da Praia também é possível fazer passeio em canoa a vela pelo riquíssimo estuário dos rios Timonhas e Ubatuba guiado por pescadores locais, assim como conhecer outras belezas, como a Praia Ponta do Saco, um sítio arqueológico catalogado pelo Iphan, no qual o turista toma conhecimento do passado, através de

Imagem 5 - Cajueiro Rei, localizado em Cajueiro da Praia.

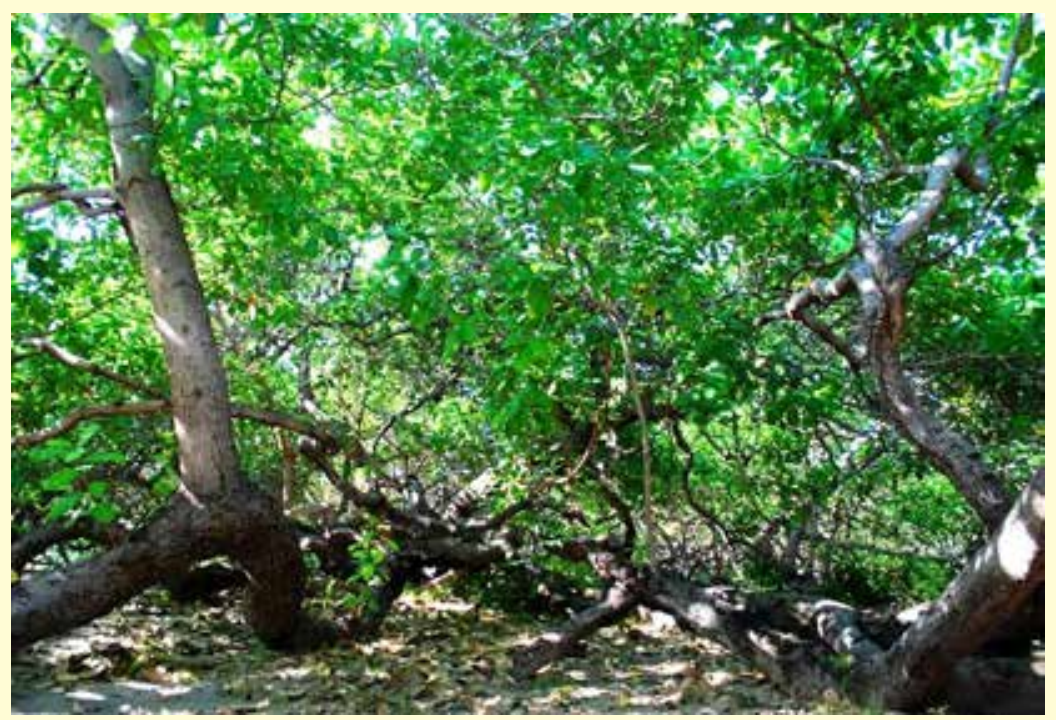

Fonte: Jornal da Parnaíba (2015). registros humanos em pedaços de cerâmica. Assim, o município resguarda formações geológicas e fisiográficas e áreas bem delimitadas que constituem o habitat de espécies animais ou vegetais em risco, e de valor incalculável do ponto de vista da ciência e da conservação.

Existe também no município de Cajueiro da Praia um cajueiro com cerca de 200 anos de idade, denominado Cajueiro Rei, que se espalha por uma área superior a 6.400 metros, conforme demonstrado na Imagem 5. Nascido de uma só castanha, a árvore ainda se encontra em processo de crescimento através da clonagem multiplicada de seus galhos, nascendo cópias idênticas ao tronco principal que lhe deu origem ${ }^{7}$.

O Cajueiro-Rei, árvore símbolo do

\footnotetext{
7 Este processo acontece porque originalmente o cajueiro espalhou-se em ramificações por reprodução não-sexual, chamada alporquia de solo, método que os chineses conhecem há séculos. A multiplicação por alporquia de solo naturalmente acontece quando os galhos tocam o chão, são recobertos pela terra úmida e ganham raízes próprias, em média, depois de dois anos ou dois invernos seguidos. Quando o galho brota, reforça seu tronco, emite novas ramificações e começa tudo outra vez. Isso proporciona uma soma biológica na captação geral de energia solar, água e nutrientes minerais distribuídos por toda a planta-mãe, tornando o cajueiro de milhares de galhos e milhões de folhas uma árvore única, resultado de múltiplas propagações.
} 
município de Cajueiro da Praia, foi destaque em matérias na imprensa nacional por ameaçar o título de o maior cajueiro do mundo de uma árvore que possui o mesmo processo de reprodução assexuada na praia de Pirangi, localizada na cidade de Parnamirim (RN).

Por ser patrimônio natural e turístico de Cajueiro da Praia, protegido por Lei Municipal, a Prefeitura de Cajueiro da Praia, junto com órgãos estaduais e federais e instituições de ensino, estão promovendo uma pesquisa para comprovar que o Cajueiro-Rei é, de fato, maior do que o Cajueiro de Pirangi. Segundo dados preliminares, a extensão do cajueiro piauiense é de 8,8 mil metros quadrados, enquanto o do RN possui 8,5 mil metros quadrados.

Outras possibilidades de exploração de atividades turísticas na Praia de Barra Grande são a caminhada e a canoagem, através de passeios às Ilhas das Garças, das Cabras e do Camaleão. Pode-se também observar e admirar a pesca tradicional, atividade ligada às origens da localidade, e a coleta de mariscos feita pelas marisqueiras, esposas dos pecadores, como atividade comercial utilizada para complementar a renda familiar.

Tanto na visitação do Projeto Peixe-boi marinho como no passeio pela Trilha Ecológica do Cavalo Marinho, os condutores reforçam a questão da biodiversidade local e preservação ambiental. Assim, os moradores locais organizam, disciplinam e orientam os turistas por meio de passeios turísticos reconhecendo o valor da biodiversidade e de sua preservação. Nesse sentido, o crescimento do turismo de observação, de acordo com Wilson e Tisdell (2001), se origina a partir do desenvolvimento do turismo e do desejo dos turistas em ver animais selvagens em seu estado natural. Conforme Serrano e Bruhns (1997), o ecoturismo seria a viagem responsável a áreas naturais, visando preservar o meio ambiente e promover o bem estar da população local. Segundo Trigo:

\begin{abstract}
O ecoturismo pode atuar positivamente por meio de: geração de emprego e oportunidade de trabalho para a comunidade local junto a atividades com fornecedores de serviços ao ecoturismo, geração de oportunidades de negócios e iniciativas empreendedoras em escala local para atender as demandas de serviços e produtos geradas pelo ecoturismo, apoio à melhoria do nível de educação da comunidade e catalização de meios para a capacitação profissional daqueles que precisam e desejam inserir-se ao mercado de trabalho em torno do ecoturismo e estímulo e fomento ao associativismo e ao espírito cooperativo nas comunidades, como forma de organização social e política para conquistar sua autodeterminação no processo de desenvolvimento ecoturístico (TRIGO, 2005, p. 486).
\end{abstract}

Assim, o ecoturismo, além de gerar benefícios para estas associações, promove certas mudanças no comportamento dos turistas no que ser refere à preservação e conservação da natureza como patrimônio socioambiental, estimulando, inclusive, o desenvolvimento de campanhas educacionais e conservacionistas do meio ambiente e a pesquisa científica, transmitindo à população a importância da preservação deste ambiente socioambiental.

Vale destacar que a área que abrange todo o município de Cajueiro da Praia, bem como toda a extensão litorânea piauiense, é dotada de raras belezas cênicas e que, certamente, em razão da crescente procura para a prática do turismo e do lazer, podem ser degradadas caso não sejam objeto de maior proteção por parte, principalmente, do poder público do estado do Piauí e da Prefeitura Municipal de Cajueiro da Praia, por meio de campanhas de sensibilização e conscientização da preservação destes ambientes, associadas aos diferentes segmentos do turismo.

Entretanto, toda a área deverá ser manejada de acordo com o Plano de Manejo da APA Polo Costa do Delta, fazendo com que a área de ampliação proposta atenda os critérios conservacionistas, tendo em vista a sua importância e fragilidade ambiental. Nesse sentido, é essencial que sejam definidos e estabelecidos "setores/zonas" dentro destas unidades de conservação, para então definir objetivos de manejo e normas específicas para cada uma, seguindo o descrito no Sistema Nacional de Unidades de Conservação da Natureza (SNUC).

Nesse sentido, os meios e as condições para cumprir os objetivos de cada unidade deverão ser definidos através da implantação de Planos Estratégicos do Turismo consistentes, que busquem criar processos integrados e com dinâmicas próprias, cujo foco principal de atuação deve ser a articulação de planos 
Dossiê

estratégicos desencadeadores de ações que envolvam questões sociais, econômicas, naturais, democráticas e sustentáveis do território turístico.

Os Corredores Amigáveis da Biodiversidade (CAB), localizados no município de Cajueiro da Praia, são configurados como corredores ecológicos constituídos por ecossistemas naturais ou seminaturais (trilhas do cavalo marinho, por exemplo), e podem ser preservados através de Áreas de Proteção Permanente (APP's) ligadas às unidades de conservação (UCs), possibilitando e facilitando, caso haja a necessidade num futuro próximo, a dispersão de espécies e a recolonização de áreas degradadas do litoral piauiense.

Assim, a implantação destas UCs, em conjunto com as ações propostas para conservação da área do município de Cajueiro da Praia, deverão proteger os recursos naturais importantes para a manutenção de uma série de serviços ambientais fundamentais para o equilíbrio ecológico e para a saúde e economia do trade local, especialmente para a comunidade, que deve participar de todas as fases desses processos para legitimá-lo, atrair o turismo ecológico e promover o desenvolvimento social e econômico de forma sustentável para a região.

Desta forma, o município de Cajueiro da Praia possui um território de valor histórico-cultural e ambiental significativos, com manifestações culturais, entendidas como tradições, práticas e referências; bens intangíveis, que conferem identidade ao município; assim como ambiências históricas e culturais; parques naturais; patrimônio arqueológico; sítios históricos e paisagens, ou seja, possui os elementos que compõem o Patrimônio Histórico-Cultural e o Patrimônio Natural, e devem ser inventariados e identificados em lei específica, com critérios de classificação, parâmetros e mecanismos de preservação, conservação e recuperação proporcionais à sua importância. Portanto, o município de Cajueiro da Praia deve ser reconhecido como patrimônio socioambiental independentemente do grau de conhecimento que se tem sobre suas inúmeras e variadas formas de utilização, devendo sua preservação partir da consciência e do orgulho de todos, para que isto seja transmitido para os turistas e, principalmente, para as futuras gerações da região.

\section{Considerações finais}

Cajueiro da Praia reúne características físicas, biológicas e geológicas extraordinárias, habitats de espécies animais ou vegetais em risco, e áreas de grande valor do ponto de vista científico e estético ou do ponto de vista da conservação.

O município é caracterizado por formações geológicas, tais como o sítio arqueológico catalogado pelo Iphan na praia da Ponta dos Sacos, onde o turista pode encontrar vestígios do passado, através de registros humanos em pedaços de cerâmica, e por conter áreas bem delimitadas que constituem o habitat de espécies de animais ou vegetais em risco de extinção e de valor incalculável do ponto de vista da ciência e da conservação, como é o caso do peixe-boi, do cavalo-marinho e da tartaruga de couro, tornando-se extremamente importante para a conservação in situ da diversidade biológica.

Nas praias cajueirenses, especificamente em Barra Grande, os moradores locais organizam, disciplinam e orientam os turistas por meio de passeios turísticos que promovem o reconhecimento do valor da biodversidade e sua consequente preservação. Assim, o ecoturismo, que se destaca dentre os diversos segmentos do turismo no município de Cajueiro da Praia, pode promover a responsabilidade social, estimular o desenvolvimento de campanhas educacionais e conservacionistas do meio ambiente e a pesquisa científica, transmitindo às populações a sua importância como patrimônio socioambiental.

Apesar destas ações, ainda são necessárias campanhas de sensibilização e conscientização ambientais mais eficazes do poder público do estado do Piaú e da Prefeitura Municipal de Cajueiro da Praia que promovam, de fato, o turismo na região de maneira sustentável e que tenham a participação efetiva das comunidades locais em todas as etapas deste processo. Também é necessário ampliar as ações das Unidades de Conservação do município de Cajueiro da Praia para garantir a preservação das características naturais do Município de Cajueiro da Praia como um patrimônio socioambiental. 


\section{Referências:}

ANJOS, Francisco Antonio dos. Processo de Planejamento e Gestão do Território Turístico: Uma Proposta Sistêmica. 2004. Tese (Doutorado em Engenharia de Produção) - Universidade Federal de Santa Catarina, Florianópolis. 2004.

BARBOSA, A. G. P.; PERINOTTO, A. R. C. Trilha Ecológica do Cavalo Marinho: ecoturismo em Barra Grande-PI. Revista Rosa dos Ventos, Caxias do Sul, v. 1, n. 1, p. 45-55, jan./jun. 2010.

BENI, Mario C. Análise Estrutural do Turismo. São Paulo: Senac, 2001.

BAPTISTA, J. G. Geografia Física do Piani. 2. ed. Teresina: COMEPI,1981. 366 p.

CARVALHO, Stella Maria Sousa. Possibilidades e limitações do desenvolvimento sustentável no município de Cajueiro da Praia (PI). 2010. Dissertação (Mestrado em Desenvolvimento e Meio Ambiente) - Universidade Federal do Piauí, Teresina. 2010.

CASTRO, A.A.J.F. Unidades de planejamento: uma proposta para o estado do Piauí com base na dimensão diversidade de ecossistemas. Publ. avulsas conserv. Ecossistemas, Teresina, n.18, p.1-28, set. 2007. (Série: Publicações Prévias).

CAVALCANTI, A. P. B. Impactos e condições ambientais da zona costeira do estado do Piauí. 2000. 356 fls. Tese (Doutorado em Geografia) - Universidade Estadual Paulista, Rio Claro. 2000.

CEPRO. Macrozoneamento costeiro do estado do Piauí: relatório geoambiental e sócioeconômico. Teresina: Secretaria de Planejamento do Piauí, 1996.

COSTA, A.S. Turismo e Desenvolvimento Sustentável em Barra Grande - Cajueiro da Praia (PI). 2006. 105 fls. Dissertação (Mestrado em Meio Ambiente e Desenvolvimento) - Universidade Federal do Piauí, Teresina. 2008.

DECLARAÇÃO DE CARACAS, 1992. Tradução de Maristela Braga. In: ARAÚJO, Marcelo Mattos; BRUNO, Maria Cristina Oliveira (Orgs.). A memória do pensamento museológico contemporâneo. Documentos e depoimentos. [S.1]: Comitê Brasileiro do ICOM, 1995.

DELPHIN, C.F de Moura. O Patrimônio Natural no Brasil. Rio de Janeiro: Iphan, 2004.

FERNANDES, Lissa V.; VIRGINIO, Darlyne F. Responsabilidade socioambiental na hotelaria: um estudo na via costeira de Natal - RN. Caderno Virtual de Turismo, Rio de Janeiro, v. 11, n. 2, p.220-233, ago. 2011.

GUZZI, Anderson. Biodiversidade do Delta do Parnaíba: litoral piauiense. In: . (Org.). Parnaíba: EDUFPI, 2012. 466p. il.

IBGE - Instituto Brasileiro de Geografia e Estatística. Censo Cidades. Disponível em: < http://www.cidades.ibge.gov. br $/$ xtras/perfil.php?lang $=\&$ codmun $=220208>$. Acesso em: 20 jan. 2010.

JACOMINE, P.K.T. et al. Levantamento exploratório - reconhecimento de solos do estado do Piauí. Rio de Janeiro: Embrapa/SNLCS/Sudene, 1986. 782 p.

KOTLER, Philip. Administração de Marketing: Análise, Planejamento, Implementação e Controle. São Paulo: Atlas, 1996.

LOPES, Francysco R. A. As dinâmicas socioespaciais em Barra Grande - PI: Um estudo introdutório do turismo e comunidade local. Revista FSA, Teresina, v. 9, n. 1, p. 113-124, jan./jul. 2012.

MACEDO, Erminia Medeiros. O turismo na Praia Grande de Barra Grande/PI: impactos e contribuições ao desenvolvimento local. 2012. Dissertação (Mestrado em Turismo) - Universidade de Brasília, Brasília. 2012.

NETO, A. Luis Correa \& Cajueiro da Praia: Executivo e Legislativo. Teresina: Geração 70, 2006.

PDITS, Polo Costa do Delta. Disponível em: < http://www.bnb.gov.br/content/aplicacao/prodetur/downloads/gerados/pdits piaui.asp>. Acesso em: 15 abr. 2015.

SERRANO, C. M. T.; BRUHNS, H. T. (Orgs.). Viagens à Natureza: Turismo, Cultura e Ambiente. 2. ed. Campinas: 
Dossiê

Papirus, 1997. 150 p. (Coleção Turismo).

PIAUÍ. Secretaria Estadual de Turismo. Municípios. Cajueiro da Praia. Disponível em: < $\underline{\text { http://www.turismo.pi.gov. }}$ br/pt-br/municipios/cajueiro-da-praia >. Acesso em: 15 abr. 2015.

SOUSA, M. J. N.; RODRIGUES NETA, F. R. Litoral do Piauí: configuração e caracterização dos atributos geoambientais. In: CEPRO, X. Macrozoneamento Costeiro do Estado do Piaui: relatório geoambiental e socioeconômico. Teresina: Fundação SEPRO, 1996. p. 43-72.

TRIGO, L. G.G. Análises Reginonais e Globais do Turismo Brasileiro. São Paulo: Roca, 2005.

UNESCO. Convenção sobre a Proteção do Patrimônio Cultural e Natural. [S.1.]: Unesco, 1972.

WILSON, C.; TISDELL, C. Sea turtles as a non-consumptive tourism resource especially in Australia. Tourism Management, Department of Economics, University of Queensland, Brisbane, v. 22, n. 3, p. 279-288, 2001. 